\title{
TOWARDS DEVELOPMENT AND VERIFICATION OF ADVANCED OPTIMAL FARM MACHINERY ROUTE ALGORITHM
}

Tomáš ŘEZNÍK ${ }^{1}$, Martina KLOCOVÁ ${ }^{1}$, Filip LEITNER ${ }^{1}$, Tomáš PAVELKA ${ }^{1}$, Lukáš HERMAN ${ }^{1}$, Jakub HRÁDEK ${ }^{1}$, Šimon LEITGEB ${ }^{1}$, Kateřina TROJANOVÁ ${ }^{1}$, Milan KONEČNÝ ${ }^{1}$

${ }^{1}$ Department of Geography, Faculty of Science, Masaryk University, Kotlářská 2, Brno, 61137, Czech Republic

Correspondence to: Tomáš ŘEZNÍK¹ (tomas.reznik@sci.muni.cz)

https://doi.org/10.31490/9788024845050-13

\begin{abstract}
Efforts related to minimising the environmental burden caused by agricultural activities are key contemporary drivers in the precision agriculture domain. Controlled Traffic Farming (CTF) techniques are being applied against soil compaction creation, using on-line optimization of route planning for soil-sensitive field operations. The research presented in this paper aims at optimizing farm machinery routes to minimize the environmental burden. As such, it further advances existing CTF solutions by its complexity including (1) efficient field divisions, (2) U-turns in headlands, (3) obstacles in a farm machinery route and (4) terrain specifics. The developed algorithm is expressed as UML activity diagrams as well as pseudo-code. Results were visualized in $2 \mathrm{D}$ and $3 \mathrm{D}$ to demonstrate terrain impact. Verifications were conducted at a fully operational commercial farm (Rostěnice, the Czech Republic) against second-by-second sensor measurements of real farm machinery trajectories. The developed algorithm addresses two main viewpoints: economic (saved route, fuel and time) and environmental (among other, reductions of soil compactness and erosion, an increase of soil infiltration rate).
\end{abstract}

Keywords: Controlled Traffic Farming, semi-autonomous driving, navigation.

\section{INTRODUCTION}

Decreasing soil health causes, among others, a barrier to producing more high-quality food, which has become a widespread challenge across the world. Soils' importance is evident as it is one of the critical factors for all living things, humankind included, to stay alive. For that reason, issues related to soil health and its higher productivity are defined in countless legally-binding documents, scientific papers, strategies, best practices, models, applications etc. The majority of (developed) countries address soil productivity and health on a legislative basis. Research funded by the European Commission (1991) has concluded that six major threats place soil fertility at risk: soil erosion, loss of organic matter, soil biodiversity, soil compaction, soil salinity and soil pollution. These threats have adverse effects on soil functions and ecosystem services, which may lead to land degradation.

Controlled traffic farming (CTF) is a strategy to minimise soil compaction, which is being implemented worldwide. CTF systems use modular working width and traffic gauge equipment, together with precise guidance to constrain all load-bearing traffic to permanent 
lanes. Most of the current work (i.e., Biglarbegian and Al-Turjman, 2014, Jin and Tang, 2010, Kroulík et al. 2018, Noguchi and Terao, 1997, Oksanen and Visala, 2009; Yan et al., 2008; presents a quantitative evaluation of the impact of CTF on the soil quality. There is a lack of valuable models that jointly combine the soil properties and the optimal CTF strategies.

The main goal of this paper is to develop a proof-of-concept for optimising farm machinery routes. The chief motivation is to reduce the risk of soil compaction creation. Fuel reductions, saving time as well as human and financial resources (e.g., lowering machinery wear) are effects of the chosen approach. The main objective was further developed into the following partial goals:

(1) Identify the input requirements for designing an algorithm for optimizing farm machinery routes.

(2) Formalise the identified requirements as a basis for their automatization.

(3) Compare the differences of theoretically optimal routes of a farm machine to reference farm machinery trajectories in the pilot area.

\section{METHODOLOGY}

\subsection{Reference farm machinery trajectories}

Reference data acquisition was conducted at the Rostěnice cooperative farm in the southeastern part of the Czech Republic. Data were measured by a CASE IH AXIAL FLOW 9120 field harvester equipped with an AFS Pro 700 monitoring unit for three fields: Lány, Pivovárka and Přední Prostřední. The measurements were of GNSS-RTK quality (Global Navigation System of Systems - the Real-Time Kinematics), i.e. they provided a spatial resolution of less than $0.1 \mathrm{~m}$. Measurements were taken continuously each second at an average speed of $1.55 \mathrm{~m} . \mathrm{s}^{-1}$, recommended as optimal at the Rostěnice Farm for cereal harvesting by the CASE IH AXIAL FLOW 9120 field harvester.

\subsection{Development of optimal farm machinery algorithm}

The following functional requirements were identified for the development of optimal farm machinery route that is applicable to plant production on the fields:

- Efficient field divisions: field fragmentation in line with terrain characteristics.

- Whole production harvest: $100 \%$ of the cultivated crop needs to be harvested.

- Avoid long-term obstacles: long-term obstacles in the field need to be addressed automatically.

- Minimization of overall trajectory length: trajectory length should be kept at a minimum as its route length affects fuel consumption, $\mathrm{CO}_{2}$ emissions and operating time.

- Minimization of the number of passes: reducing soil compaction.

- Selection of appropriate U-turn shape: in line with research developed by Jin and 
Tang (2010).

- Adaptability to specific crops: a selection of relevant farm machinery (such as vehicle width, axle load, tire pressure).

- Terrain impacts:

- steepness of the slopes as two key inputs to address erosion,

o selection of a field entry/exit points according to their altitude.

The methodology used in this paper followed the 'waterfall approach' as described by Royce (1970). The requirements were transformed into a functional specification where each requirement mentioned above was formally defined as a stand-alone function. The developed functional specification consists of sets of UML activity diagrams. The pseudocode was created for the optimal farm machinery route algorithm.

Manually-created trajectories were visualized when following the developed algorithm. Such routes were verified against second-by-second sensor measurements of real farm machinery trajectories and by agronomists at farm Rostěnice.

\section{RESULTS}

Five main results were achieved during the optimal farm machinery route algorithm development:

- UML activity diagram expressions documenting the developed algorithm (see the overall level of detail in Figure 1 as an example),

- pseudo-code of the developed algorithm,

- trajectories created according to the developed algorithm (since the used procedure is designed as parameterizable and scalable, there are several trajectory variants as shown in Table 1 together with Figures 2 and 3),

- comparison of measures calculated from both types of trajectories (trajectories lengths, number of turns and elevation gain),

- 2D and 3D cartographic outputs.

The methodology of optimizing farm machinery route has been designed as a generally applicable to any field(s). As such, the methodology consists of modules to provide customizable solutions.

Data import module loads data, which are required as a prerequisite to run the presented algorithm. Parameters settings module define input parameters like span length of a machine operating on a field. Plot fragmentation module simplifies the field geometry by splitting to smaller fragments when three options are possible (based on aspect, slope or field shape). Fragmentation into two parts based on field shape was used for creating 'OPTI 2 ' trajectory as depicted in Figure 2 (bottom). Trajectory calculation is the core module, which creates the optimal trajectory. Module Bypass the obstacles adjusts the previously calculated trajectory to avoid possible obstacles. 


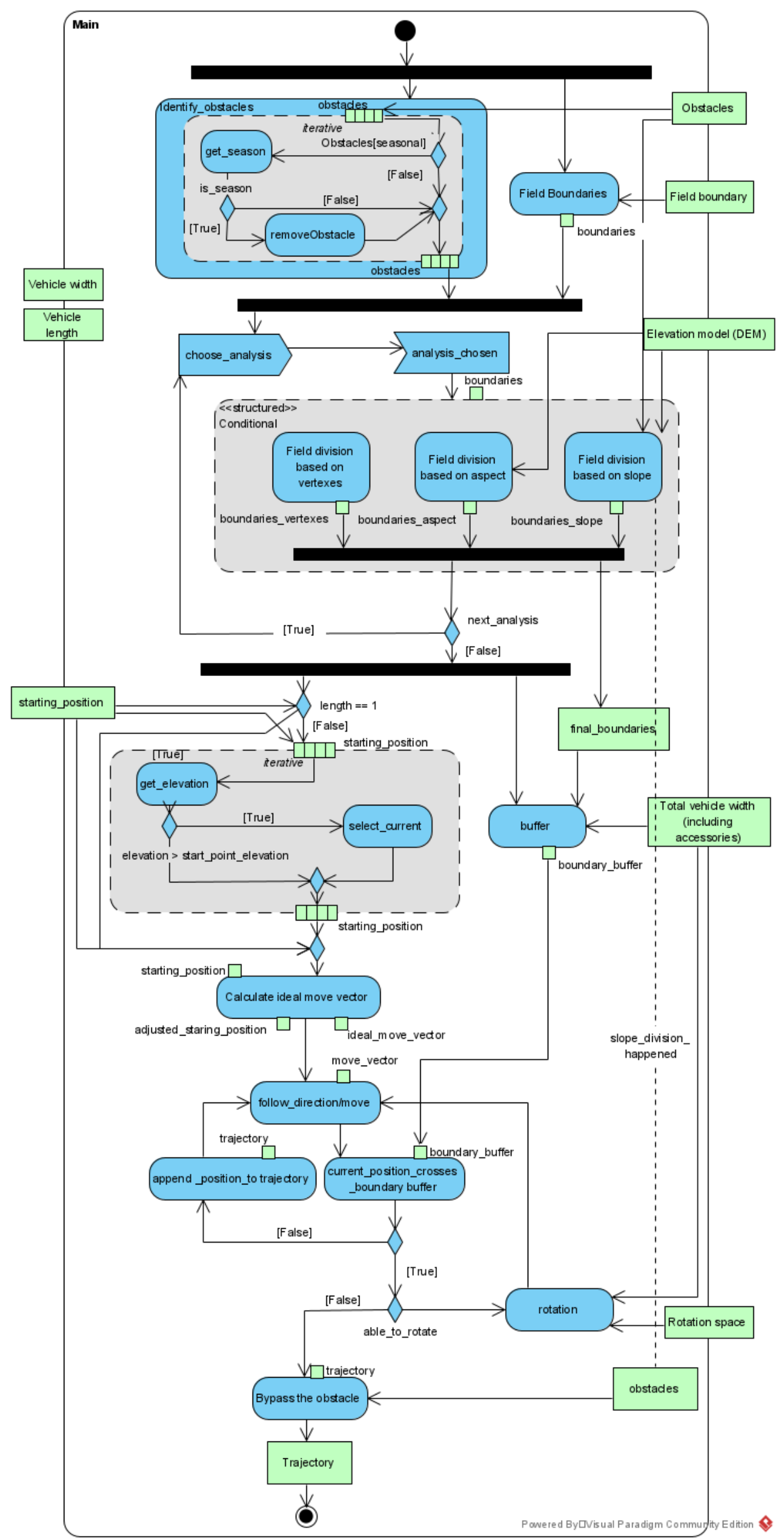

Figure 1. Overall UML activity diagram of optimal farm machinery route algorithm. 
Pseudo-code was divided into identical building blocks as defined in the methodology. The resulting pseudo-code depicted in Listing 1 originates from the Structured basic style pseudo-code mixed with notes (comments) expressed in natural language descriptions.

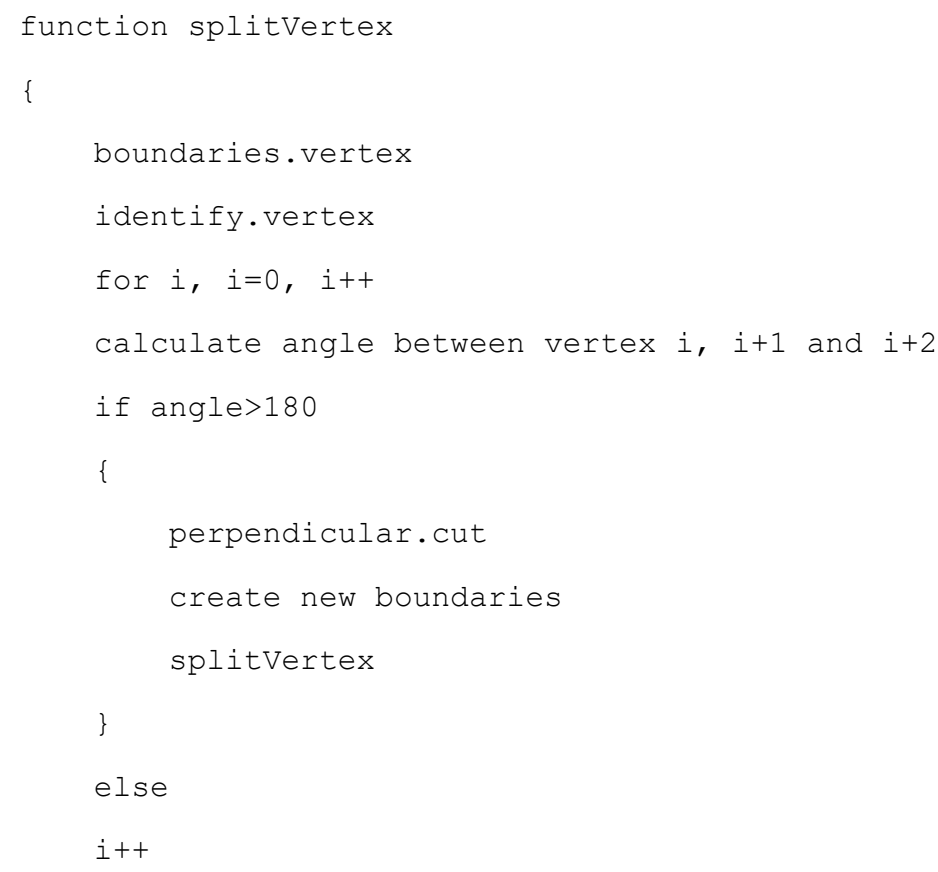

Listing. 1. Part of a pseudo-code for optimal farm machinery route algorithm (a function of field splitting with complex shape into sections).

Relative differences were used for comparison of $(A)$ different variants of manually created trajectories according to the developed pseudo-code and (B) second-by-second sensor measurements of real farm machinery trajectories for three fields at Rostěnice farm (see Table 1).

Table 1. Descriptive statistics of reference (REAL) and modelled farm machinery trajectories (OPTI 1 and OPTI 2) for Pivovárka field (Rostěnice cooperative farm, Czech Republic). Note 'N/A' stands for 'not applicable'.

\begin{tabular}{lcccccc}
\hline \multirow{2}{*}{ Trajectory } & \multicolumn{2}{c}{ Length } & \multicolumn{2}{c}{ Turns } & \multicolumn{2}{c}{ Elevation } \\
\cline { 2 - 7 } & $\begin{array}{c}\text { Length } \\
{[\mathrm{m}]}\end{array}$ & $\begin{array}{c}\text { Difference } \\
{[\%]}\end{array}$ & Number & $\begin{array}{c}\text { Difference } \\
{[\%]}\end{array}$ & $\begin{array}{c}\text { Gain } \\
{[\mathrm{m}]}\end{array}$ & $\begin{array}{c}\text { Difference } \\
{[\%]}\end{array}$ \\
\hline REAL & $59,762.16$ & N/A & 93 & N/A & $2,074.79$ & N/A \\
\hline OPTI 1 & $50,623.76$ & -15.29 & 67 & -27.96 & $1,818.85$ & -12.34 \\
\hline OPTI 2 & $50,588.15$ & -15.35 & 121 & 30.11 & $1,751.85$ & -15.57 \\
\hline
\end{tabular}



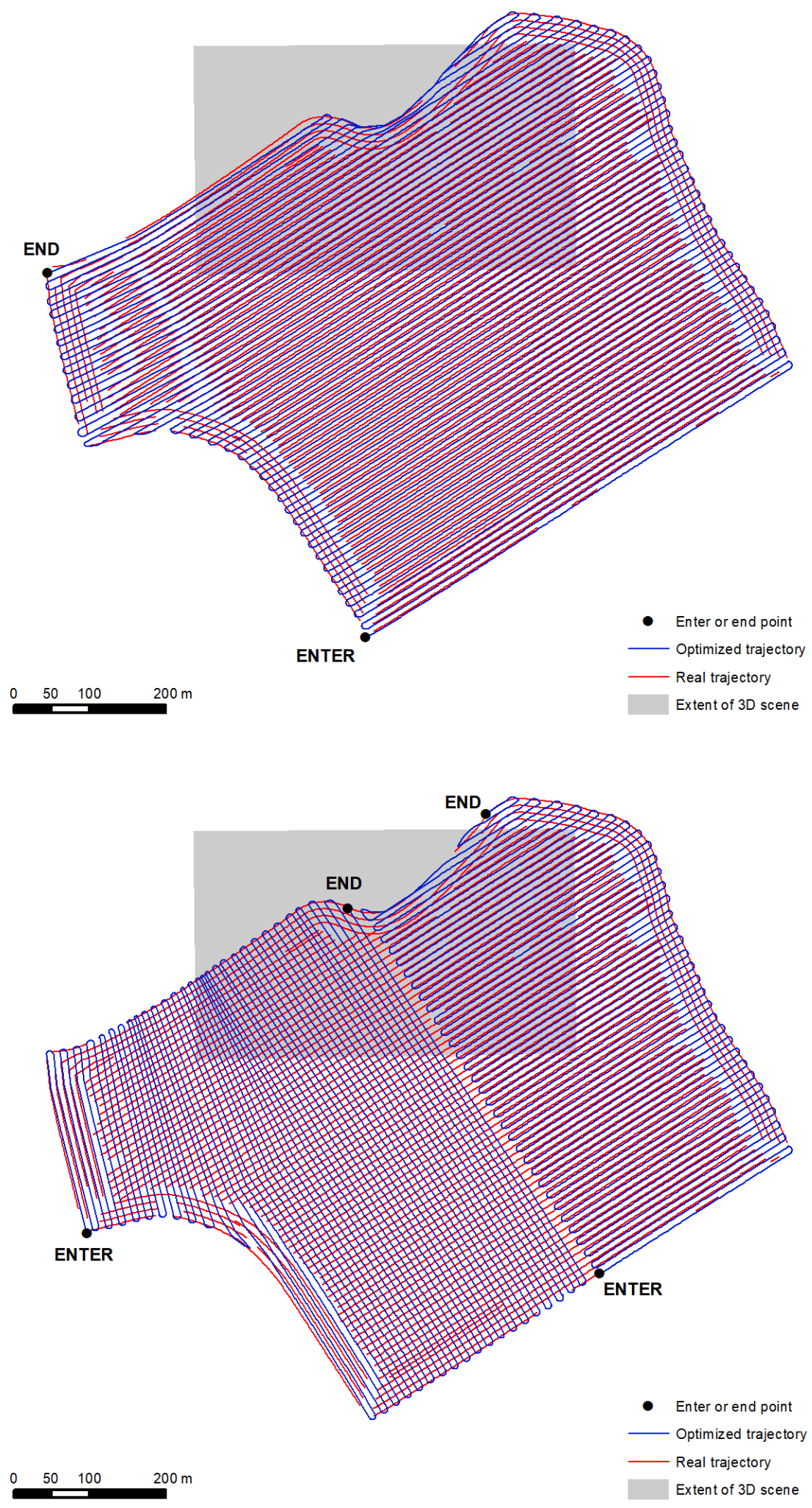

Figure 2. 2D overview visualizations of reference (real) trajectory and two variants of optimised trajectories (top - OPTI 1; bottom - OPTI 2) in Pivovárka field (Rostěnice cooperative farm, Czech Republic). Note that the grey rectangle represents the approximate extent of the 3D scene depicted in Figure 3. 


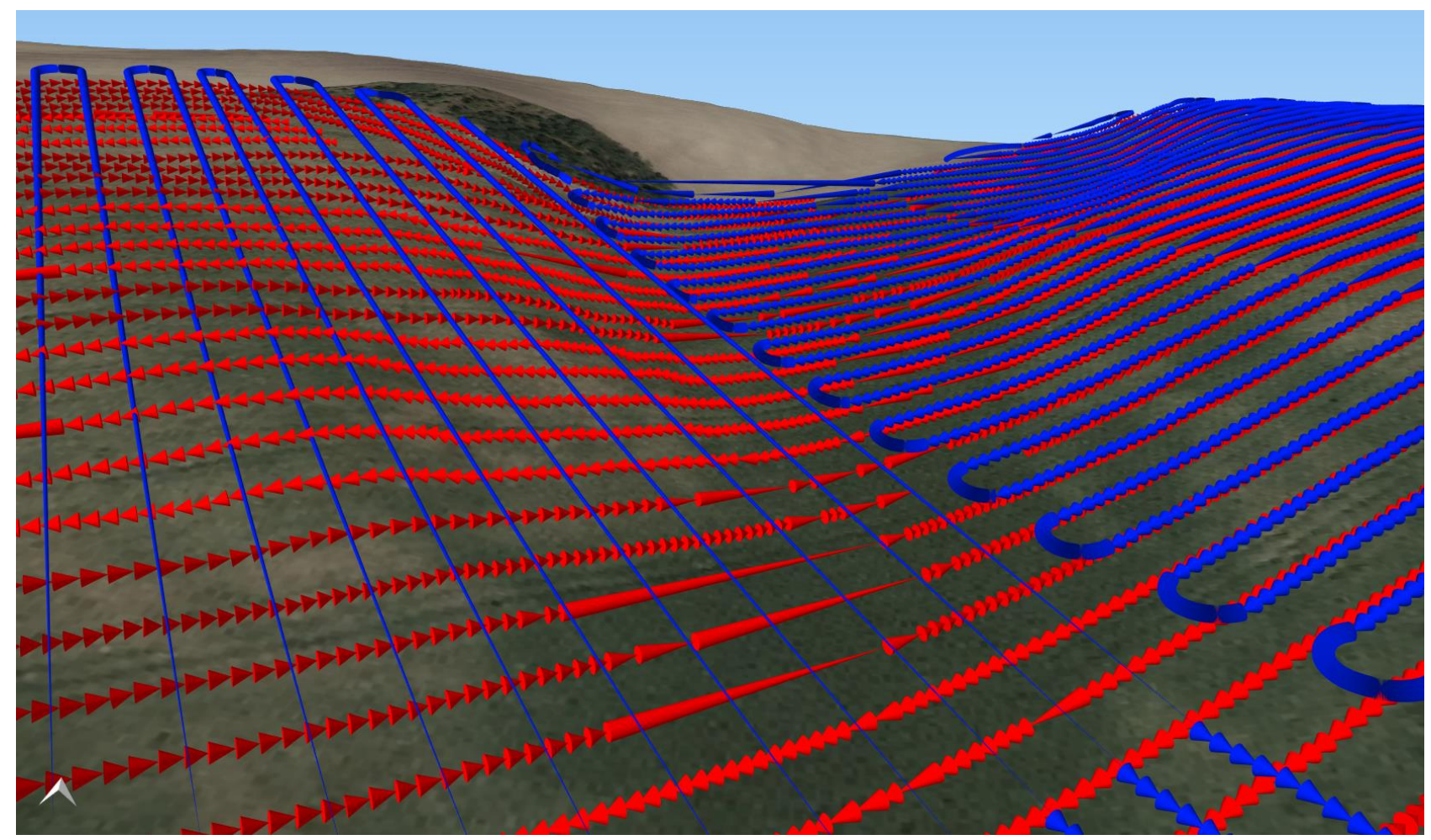

Figure 3. Detailed 3D visualization of real trajectory (red colour) and optimised trajectory 'OPTI 2' (blue) in Pivovárka field (Rostěnice cooperative farm, Czech Republic).

\section{CONCLUSIONS}

The developed algorithm addresses two main viewpoints: economic (saved route, fuel and time) and environmental (among other, reductions of soil compactness and erosion, an increase of soil infiltration rate).

The following major advantages of the developed algorithm were identified:

- complexity, as it planes the route, including the definition of the direction of passes, avoiding obstacles and turns definition,

- procedure is designed as platform-independent and open,

- it enables processing of more complex field shapes, by dividing into segments,

- it considers the morphometric characteristics of the terrain (slope).

The following major differences between theoretically optimal and real reference farm machinery trajectories were identified:

- theoretically optimal routes of a farm machine developed in line with the presented algorithm is about $15 \%$ shorter than the reference farm machinery trajectories. On the contrary, the number of turns of theoretically optimal routes is higher by around $30 \%$ than in the cases of reference farm machinery trajectories,

- differences between theoretically optimal and reference farm machinery trajectories result from the following reasons: (1) the reference farm machinery trajectories overlapped in several cases together with (2) longer turns. 
The developed algorithm is designed for planning of farm machinery movement. The functionality of the algorithm has been tested on pilot fields from the Rostěnice cooperative farm. The algorithm is still a proof of concept, the possible modifications and extension will be the subject of follow-up research.

\section{ACKNOWLEDGMENTS}

This paper is part of a project that has received funding from the European Union's Horizon 2020 research and innovation program under grant agreement No. 818346, called "Sino-EU Soil Observatory for intelligent Land Use Management" (SIEUSOIL).

\section{REFERENCES}

Biglarbegian, M., Al-Turjman, F. (2014) Path planning for data collectors in Precision Agriculture WSNs. IWCMC 2014 - 10th International Wireless Communications and Mobile Computing Conference, Nicosia, Cyprus, 4-8 August 2014, IEEE, Piscataway, NJ, USA, pp. 483-487.

European Commission (1991) Council Directive of 12 December 1991concerning the protection of waters against pollution caused by nitrates from agricultural sources. https://eur-lex.europa.eu/legal-content/EN/TXT/PDF/?uri=CELEX:01991L067620081211\&from=EN [7 January 2021].

Gutman, P., loslovich, I. (2013) Inter-field routes scheduling and rescheduling for an autonomous tractor fleet at the farm. 2013 18th International Conference on Methods \& Models in Automation \& Robotics (MMAR), Miedzyzdroje, Poland, 26-29 August 2013, IEEE, Piscataway, NJ, USA, pp. 812-817.

Jin, J., Tang, L. (2010) Optimal Coverage Path Planning for Arable Farming on 2D Surfaces. Transactions of the ASABE, 53, 283-295.

Kroulík, M., Hula, J., Brant, V. (2018) Field trajectories proposals as a tool for increasing work efficiency and sustainable land management. Agronomy Research, 16, 17521761.

Noguchi, N., Terao, H. (1997) Path planning of an agricultural mobile robot by neural network and genetic algorithm. Computers and Electronics in Agriculture, 18, 187-204.

Oksanen, T., Visala, A. (2009) Coverage Path Planning Algorithms for Agricultural Field Machines. J. Field Robotics, 26, 651-668.

Royce, W. (1970) Managing the Development of Large Software Systems. https://leadinganswers.typepad.com/leading answers/files/original waterfall paper wi nston royce.pdf [7 January 2021].

Yan, H., Wang, H., Chen, Y., Dai, G. (2008). Path Planning Based on Constrained Delaunay Triangulation. 7th World Congress on Intelligent Control and Automation, Chongqing, China, 25-27 June 2008, IEEE, Piscataway, NJ, USA, pp. 5168-5173. 